\title{
Uso de Poli-hidroxibutirato e Norbixina como Biomaterial para Regeneração Óssea: um mapeamento tecnológico
}

\section{The Therapeutic Potential of Poly (Hydroxybutyrate) and Norbixin as Biomaterial Scaffold for Bone Repair: a technological mapping}

\author{
Rayssilane Cardoso de Sousa ${ }^{1}$ \\ Vicente Galber Freitas Viana ${ }^{2}$ \\ Luiz Fernando Meneses Carvalho ${ }^{2}$ \\ Daniel Fernando Pereira Vasconcelos ${ }^{1}$ \\ ${ }^{1}$ Universidade Federal do Piauí, Teresina, PI, Brasil \\ ${ }^{2}$ Instituto Federal de Educação, Ciência e Tecnologia do Piauí, Teresina, PI, Brasil
}

\begin{abstract}
Resumo
É crescente a associação de matrizes poliméricas e extratos naturais para a confecção de novos biomateriais na área de engenharia de tecidos. O presente trabalho propõe um estudo prospectivo sobre a aplicação de uma matriz polimérica contendo poli-hidroxibutirato e o apocarotenoide norbixina como biomaterial para fins de reparo ósseo. Foram realizadas buscas de artigos científicos publicados nos últimos dez anos, entre 2008 e 2018, nas bases de periódicos Web of Science, Scopus e Scielo. Para o mapeamento científico e tecnológico, considerou-se o levantamento total do número de patentes nos bancos de patentes INPI, Espacenet e USPTO. A partir dos artigos e patentes revisados, constatou-se que a associação desses constituintes na engenharia de tecidos e em reparo ósseo é desconhecida. Porém, observou-se que eles são conhecidamente utilizados como biomateriais com relevantes propriedades terapêuticas em diversos meios biológicos, tratando-se, portanto, de uma promissora área de pesquisa a ser explorada.
\end{abstract}

Palavras-chave: Norbixina. Poli-hidroxibutirato. Reparo Ósseo.

\begin{abstract}
The association of polymeric matrices and natural extracts for the development of new tissue engineering biomaterials is growing. The present work proposes a prospective study regarding the application of a polymeric matrix containing polyhydroxybutyrate and norbixin apocarotenoid as biomaterial for bone repair purposes. Searches were carried out for scientific articles published in the last ten years, between 2008 and 2018, in the databases of Web of Science, Scopus and Scielo journals. For scientific and technological mapping, the total survey of the number of patents in the INPI, Espacenet and USPTO patent banks was considered. From the articles and patents reviewed, it was found that the association of these constituents in tissue engineering and bone repair is unknown. However, it was observed that they are known to be used as biomaterials with relevant therapeutic properties in various biological environments, thus being an association with innovative therapeutic potential, therefore, it is a promising area of research to be explored.
\end{abstract}

Keywords: Norbixin. Polyhydroxybutyrate. Bone Repair.

Área Tecnológica: Biotecnologia em Saúde. Biomaterial. Engenharia de Tecidos. 


\section{Introdução}

Apesar das inúmeras opções para tratamentos de feridas cutâneas, a engenharia de tecidos traz os biomateriais como alternativa para estímulo à regeneração e recuperação de tecidos circundantes à sua implantação. Tem sido promissor o emprego de matrizes poliméricas para esse fim, assim como extratos naturais. Para Pires, Bierhalz e Moraes (2015), biomateriais são dispositivos que entram em contato com sistemas biológicos, com aplicações diagnósticas, vacinais, cirúrgicas ou terapêuticas, e são constituídos a partir de compostos de origem natural ou sintética, bem como materiais naturais quimicamente modificados, havendo uma grande diversidade destes produtos utilizados na área da saúde visando à regeneração de um tecido funcional, capacidade de substituição do tecido danificado, suporte mecânico adequado ao paciente, além de biocompatibilidade e baixa rejeição do implante pelo organismo.

Dentre os biopolímeros utilizados como biomaterial, o poli(hidroxibutirato) $(\mathrm{PHB})\left(\mathrm{C}_{4} \mathrm{H}_{6} \mathrm{O}_{2}\right)$, é um poliéster saturado linear, parcialmente cristalino e um termoplástico sintético biodegradável que tem sido largamente empregado como matriz em sistemas biológicos (AARTHI; RAMANA, 2011; MELO et al., 2012). Polímeros dessa natureza, quando implantados em sistemas vivos, não necessitam de posterior remoção do corpo e não causam efeitos indesejáveis a longo prazo, pois apresentam redução da massa molar quando em contato com o ambiente corpóreo (ORÉFICE; PEREIRA; MANSUR, 2012).

Os polímeros sintéticos convencionais têm sido substituídos por polímeros biodegradáveis em aplicações relacionadas ao meio ambiente e ao desenvolvimento sustentável, nas quais o PHB é comumente empregado em biocompósitos, como matriz para bioplásticos e, por ser duro e quebradiço, geralmente é reforçado com fibras vegetais tratadas para melhor adesão $e$ otimização de suas propriedades (MACHADO et al., 2010; MELO et al., 2012).

Quanto à aplicação como biomaterial, materiais termoplásticos sintéticos biodegradáveis, como o PHB, têm sido utilizados em suturas, como dispositivos de distribuição controlada de fármacos, na fixação de dispositivos ortopédicos (parafusos e placas de osteossíntese), na prevenção de adesão, como matriz para engenharia de tecidos (crescimento de novos tecidos, guia à resposta tissular, fixação e proliferação celular e anti-inflamatório) (ORÉFICE; PEREIRA; MANSUR, 2012; REIS et al., 2012).

Por outro lado, a norbixina e a bixina são os principais pigmentos extraídos do pericarpo das sementes do urucum (Bixa orellana) - uma árvore nativa das Américas Central e Sul. A bixina $\left(\mathrm{C}_{25} \mathrm{H}_{30} \mathrm{O}_{4}\right)$ representa $80 \%$ dos pigmentos carotenoides encontrados no urucum e é caracterizada quimicamente como cadeia isoprênica de 25 carbonos, contendo um ácido carboxílico e um éster metílico nas extremidades. Já a norbixina $\left(\mathrm{C}_{24} \mathrm{H}_{28} \mathrm{O}_{4}\right)$ é encontrada em menores quantidades e, por conta disso, geralmente é obtida a partir da saponificação da bixina, na forma de seu derivado desmetilado, ou seja, sua cadeia apresenta apenas 24 carbonos (COSTA; CHAVES, 2005; ZHANG; ZHONG, 2013).

A norbixina é um apocarotenoide de ocorrência natural e solúvel em água (ácido dicarboxílico) que possui propriedades antioxidantes, antimicrobianas e antitumorais, as quais podem influenciar e otimizar processos de cicatrização tecidual (MUTHUKUMAR et al., 2014). Na lite- 
ratura estão relatados diversos estudos sobre avaliação dos efeitos genotóxicos, teratogênicos ou mutagênicos desse pigmento, que objetivaram avaliar as propriedades de interações dele com o meio biológico em animais (MONTE et al., 2016; MUTHUKUMAR et al., 2014; SANTOS et al., 2014; SOUSA et al., 2016).

Dentro desse contexto, esta pesquisa propõe um estudo de prospecção de patentes e artigos relacionados à aplicabilidade do biopolímero poli-hidroxibutirato associado ao apocarotenoide norbixina para fins cicatrizantes, tais como reparação de defeito ósseo.

\section{Metodologia}

Este mapeamento tecnológico consistiu de um estudo prospectivo tecnológico e científico buscando as patentes e artigos científicos relacionados com as palavras-chave propostas. Foram utilizadas as bases gratuitas INPI, Espacenet e USPTO para a busca de patentes; e utilizadas as bases de periódicos Web of Science, Scopus e Scielo para a busca de artigos (TEIXEIRA; TEIXEIRA, 2018).

Primeiramente, realizou-se a pesquisa com as palavras-chave em inglês e português: "Norbixin" (norbixina), "Polyhydroxybutyrate" (polihidroxibutirato), "Biomaterial" (biomaterial), "Tissue Engineering" (engenharia de tecidos) e "Bone Repair" (reparo ósseo). Em seguida, foram analisados as patentes e artigos obtidos com diferentes combinações destas palavras tais como: "Norbixin" AND "Polyhydroxybutyrate", "Norbixin" AND "Biomaterial", "Norbixin" AND "Tissue Engineering", "Norbixin" AND "Bone Repair", "Polyhydroxybutyrate" AND "Biomaterial", "Polyhydroxybutyrate" AND "Tissue Engineering" e "Polyhydroxybutyrate" AND "Bone Repair" para que as buscas fossem refinadas de acordo com o objetivo deste estudo. Na base gratuita do INPI, a busca de patentes também foi realizada com as palavras-chave correspondentes em português, visto se tratar de uma base nacional. Em todos os casos, as pesquisas foram delimitadas aos campos "título, resumo e palavras-chave".

Para a prospecção tecnológica, não foi delimitado tempo específico, sendo realizado o levantamento total do número de patentes, ao passo que a prospecção científica se deu com o levantamento do número de artigos científicos publicados de 2008 até o ano de 2018. As buscas nos bancos de patentes e bases científicas foram realizadas no mês de dezembro de 2018. Na base de periódicos Scopus, na qual se obteve o maior número de publicações com a palavra-chave "Norbixin", foram analisadas a quantidade de documentos por ano, os países com maiores números de publicações e as principais áreas de aplicações com esse apocarotenoide. Da mesma forma, também foram analisadas as combinações com as palavras-chaves "Polyhydroxybutyrate" AND "Biomaterial" e "Polyhydroxybutyrate" AND "Bone repair".

\section{Resultados e Discussão}

Os resultados encontrados neste estudo prospectivo tecnológico e científico foram dispostos em tabelas e em gráficos. Esses recursos foram subdivididos em tópicos quanto à análise das patentes e dos artigos publicados a seguir. 


\subsection{Análise das Patentes Publicadas}

A Tabela 1 dispõe o número de patentes encontradas nas bases europeia (Espacenet), americana (USPTO) e nacional (INPI) relacionadas às palavras-chave do trabalho. Observou-se que, em geral, a base internacional europeia apresentou o maior número de patentes e a base nacional o menor número, para todos os termos pesquisados. No INPI, o Brasil tem poucas invenções depositadas que envolvam aplicações de norbixina, embora Bixa orellana L. seja uma árvore nativa na América tropical (SANTOS et al., 2014). Na busca com a palavra-chave "Norbixin"/"Norbixina", não foi observada nenhuma invenção voltada para fins cicatrizantes. Foram encontradas patentes que a utilizam em formulações alimentícias, alimentos ou bebidas não alcoólicas, conservação de alimentos ou produtos alimentícios em geral, além de coloração de tecidos. Nesse contexto, as patentes brasileiras relacionadas à "Norbixina" foram descritas em seguida.

Tabela 1 - Número de patentes encontradas com as palavras-chave nos bancos Espacenet, USPTO e INPI

\begin{tabular}{cccc} 
Palavras-CHAVE & EsPaCENET & USPTO & INPI \\
Norbixin/Norbixina & 26 & 5 & 6 \\
\hline Polyhydroxybutyrate/Poli-hidroxibutirato & 375 & 63 & 15 \\
\hline Tissue engineering/Engenharia de tecidos & 7.139 & 522 & 64 \\
\hline Biomaterial/biomaterial & 4.714 & 614 & 88 \\
\hline Bone repair/reparo ósseo & 5.699 & 940 & 13 \\
\hline
\end{tabular}

Fonte: Elaborada pelos autores deste artigo (2018)

Nesse sentido, a invenção da UFMG (2019), BR1020160299799A2, compreende nanodispositivos poliméricos à base de polímeros biodegradáveis, polímeros termoplásticos ou não, escolhidos dentre poliésteres, polipropileno, poliamidas, polímeros acrílicos e ácido metacrílico, policarbonatos, preferencialmente policaprolactona (PCL), para a criação de nanopartículas ou nanofibras poliméricas, carregados com agentes ou compostos com propriedades adsorventes, antioxidantes, redutoras e/ou quelantes, com a presença de material adsorvente, antioxidante, redutor e quelante, o qual foi selecionado de carotenoides, preferencialmente bixina, norbixina etc.

A patente da Universite Paris 6 Pierre et Marie Curie (2018), BR1120170232642A2, refere-se ao uso de uma composição compreendendo norbixina produzida por purificação de um extrato de semente de Bixa orellana para a fotoproteção de células epiteliais do pigmento retiniano em mamíferos. A patente de CHR. Hansen Natural Colors A/S (2017), BR1120140279110A2, refere-se a uma composição vermelho-laranja compreendendo norbixina para atuar como um agente de dispersão e para ser usada na fabricação de produtos alimentícios e farmacêuticos. Levy, Binnington e Tabatznik (2004) desenvolveram a patente PI0207405-2B1, a qual produziu novos ésteres de carotenoides que incluem norbixina, bixina, crocetina, entre outros, que podem ser úteis como antioxidantes, agentes terapêuticos, ingredientes de pigmentação de alimentos ou como agentes de fixação de gordura. 
A invenção de Ferreira (2002), PI0005165-9A2, refere-se ao processo de fabricação de extratos vegetais modificados com extrato de tanino, incluindo norbixina, a fim de torná-lo mais resistente e estável para atuar em procedimentos aplicáveis, no tingimento e na coloração de fibras têxteis com diferentes tintas para vários usos. Finalmente, a invenção da empresa Viscofan (1995), PI9500660-5B1, criou um invólucro de celulose para revestimento de salsichas.

Observa-se em geral que a norbixina foi citada como aditivo nos produtos desenvolvidos a fim de otimizar suas propriedades. Em seu mapeamento prospectivo, Nascimento et al. (2018) também consideraram a tendência da indústria farmacêutica para o desenvolvimento de novos produtos biotecnológicos isolando componentes de extratos vegetais, como o própolis, por exemplo, a fim de criar inovados biofármacos mais efetivos para uso terapêutico, podendo potencializar o efeito de drogas sintetizadas quimicamente.

Para refinar ainda mais a pesquisa, foram utilizadas combinações com duas palavras-chave relacionadas à pesquisa, como pode ser verificado na Tabela 2.

Tabela 2 - Número de Patentes encontradas combinando duas palavras-chave relativas ao trabalho nos bancos Espacenet, USPTO e INPI

\begin{tabular}{cccc} 
PALAVRAS-CHAVE & ESPACENET & USPTO & INPI \\
\hline Norbixin and biomaterial / Norbixina e biomaterial & 0 & 0 & 0 \\
\hline Norbixin and tissue engineering / Norbixina e engenharia de tecidos & 0 & 0 & 0 \\
\hline Norbixin and bone repair / Norbixina e reparo ósseo & 0 & 0 & 0 \\
\hline Norbixin and polyhydroxybutyrate / Norbixina e polihidroxibutirato & 0 & 0 & 0 \\
\hline $\begin{array}{c}\text { Polyhydroxybutyrate and biomaterial / Polihidroxibutirato e biomaterial } \\
\text { Polyhydroxybutyrate and tissue engineering / } \\
\text { Polihidroxibutirato e engenharia de tecidos }\end{array}$ & 0 & 0 & 0 \\
\hline $\begin{array}{c}\text { Polyhydroxybutyrate and bone repair / } \\
\text { Polihidroxibutirato e reparo ósseo }\end{array}$ & 8 & 0 & 1 \\
\hline
\end{tabular}

Fonte: Elaborada pelos autores deste artigo (2018)

Nenhum resultado foi refinado nos três bancos pesquisados a partir das combinações "Norbixin" AND "Biomaterial", "Norbixin" AND "Tissue engineering", "Norbixin" AND "Bone repair", assim como também não foi encontrado "Norbixin" AND "Polyhydroxybutyrate" (Tabela 2), o qual é o objetivo do desenvolvimento desta pesquisa. Por outro lado, quando as palavras-chave "Polyhydroxybutyrate "AND "Tissue Engineering" foram combinadas, oito patentes foram encontradas no Espacenet, além de uma patente no INPI, ou seja, um baixo número de patentes encontradas. Para Rocha, Quintella e Torres (2012), isso pode representar pendências tecnológicas a serem solucionadas.

Em síntese, na Figura 1 estão dispostos os principais países inovadores com patentes depositadas nas bases de dados analisadas, e nela pode-se verificar que a China é a maior detentora de patentes envolvendo "Polyhydroxybutyrate" AND "Tissue Engineering", com um total de cinco patentes depositadas entre 2007 e 2016. A Rússia depositou uma patente em 2012 e outra em 2016 e a Romênia uma patente em 2014, ambas na base Espacenet. O Brasil depositou uma patente no INPI em 2015. Da mesma forma, no estudo prospectivo de Rocha, Quintella e Torres (2012) sobre polímeros biocompatíveis aplicados à engenharia de tecidos 
e medicina regenerativa, a China também se revelou como importante detentora de patentes publicadas nesse âmbito. No estudo prospectivo de Azevêdo et al. (2018), a China foi o país com maior depósito de patentes envolvendo tecnologia de elaboração de biofilmes a partir de biopolímeros, como o amido.

Figura 1 - Distribuição de patentes depositadas nas bases de dados a partir das palavras-chave "Polyhydroxybutyrate" AND "Tissue Engineering" (Poli-hidroxibutirato e Engenharia de tecidos). CN (China), RU (Rússia), RO (Romênia) e BR (Brasil)

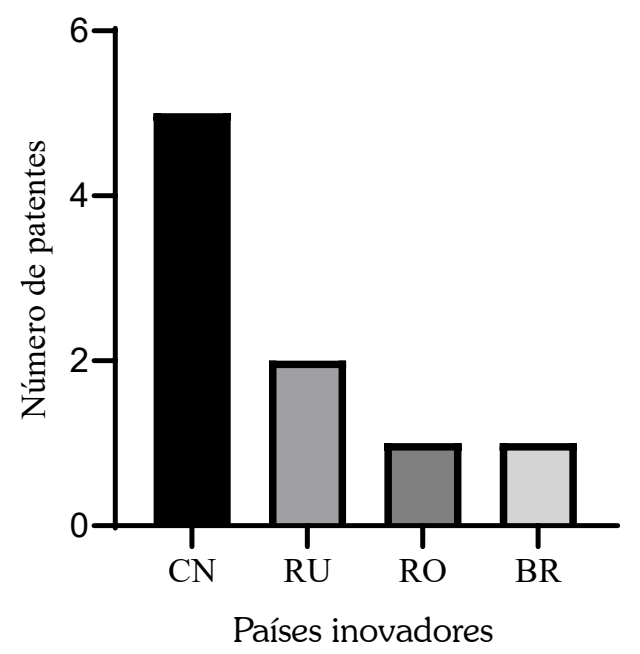

Fonte: Elaborada pelos autores deste artigo (2018)

A patente UFRGS et al. (2017), BR1020150174357A2, localizada no INPI, relaciona-se ao processo de obtenção da membrana eletrofílica do polímero PHB para o tratamento de lesões de tecidos biológicos e também um processo de regeneração ex vivo compreendendo a etapa de contato da membrana eletrofílica com pelo menos um tecido biológico. Os inventores da patente RU2016123645, Federal State Budget Scientific Institution (2017), trataram de um implante vascular biodegradável para engenharia tecidual pela técnica de electrospinning a partir da composição polimérica do valerato de poli-hidroxibutirato (PHBV) e policaprolactona (PCL) com a introdução layer-by-layer de moléculas biologicamente ativas na parede vascular. A patente de Henan Institute of Engineering (2016), CN105582577, refere-se à preparação de PHBV enxertado com nano-hidroxiapatita com potencial aplicação na engenharia de tecidos e no reparo de defeitos ósseos.

A invenção da Politehnica University of Bucharest (2015), RO130767, refere-se à composição de um polímero e seu método de preparação a partir de $\mathrm{PHB}$, celulose bacteriana e citrato tribulato para aplicações em engenharia de tecidos. A invenção de Federal New Budgetary Institution (2014), RU2504406, desenvolveu o método de preparação de um enxerto vascular reabsorvível híbrido para vasos de pequeno diâmetro utilizando a composição polimérica de PHBV e epsilon-policaprolactona com colágeno de tipo IV, fibronectina humana e fatores de crescimento de fibroblastos humanos.

Northwest Normal University Die et al. (2013) desenvolveram a patente CN103275328, a qual se trata de um método sintético de copolímero de polissacarídeo de $\mathrm{PHB}$ e Artemisia sphoerocephalia para uso como biomaterial em engenharia de tecidos. Northwest Normal University 
Die et al. (2013) também desenvolveram a patente CN103113726, a qual cita a preparação de um material híbrido baseado em PHB e betonita como compósitos para uso em engenharia de tecidos.

A invenção de Wenfang (2002), CN2475908, criou um material transportador poroso e método de preparação com PHB e polietilenoglicol adequado para o crescimento de aposição celular de tecido de cartilagem. Finalmente, a patente da Donghua University (2008), CN101147812, descreve a preparação e aplicação de um material tridimensional poroso para engenharia de tecidos a partir de PHBV e PCL.

Ainda em relação ao refinamento proposto na Tabela 2 , para a combinação das palavras-chave "Polyhydroxybutyrate" AND "Bone Repair", foram encontradas cinco patentes no banco europeu Espacenet, cujo país detentor de todas as inovações refinadas foi a China, com publicações entre 2011 e 2016. A patente CN106581774 (SUZHOU NABEITONG ENVIROMENTAL TECHNOLOGY CO. LTD, 2017) cita o método de preparação de um material de reparo ósseo injetável a partir de poli-hidroxibutirato adicionado a outros constituintes, tais como hidroxiapatita, ácido hialurônico, fibras de colágeno, dentre outros. A patente CN105582577 (HENAN INSTITUTE OF ENGINEERING, 2016) já foi descrita na pesquisa refinada para "Polyhydroxybutyrate" AND "Tissue Engineering", e diz respeito à preparação de PHBV enxertado com nano-hidroxiapatita com potencial aplicação na engenharia de tecidos e reparo de defeitos ósseos.

A invenção CN105063789 (TSINGHUA UNIVERSITY, 2015) trata-se de uma sutura absorvível contendo poli-hidroxibutirato, PHBV ou PHBHHx (poli-3-hidroxibutirato-co-3-hidroxihexanoato), e seus métodos de preparação com bom efeito no reparo de sutura em cartilagem $e$ tecido ósseo. A patente CN102973981 (SOUTHEAST UNIVERSITY, 2013) cria o método de preparação de um scaffold tridimensional com nanofibras pela tecnologia de electrospinning capaz de promover a reparação óssea a partir de um copoliéster de $\mathrm{PHBV}$, polioxietileno e hidroxiapatita.

A patente CN102166372 (SOUTHEAST UNIVERSITY, 2011) fornece uma metodologia para a invenção de scaffolds PHBV compostos de nanofibras de hidroxiapatita (nHA) para reparar defeitos ósseos críticos usando tecnologia de electrospinning direcional e não direcional, sendo o efeito de reparo dos scaffolds direcionais melhor que o não direcional, contudo, o módulo de elasticidade dos scaffolds não direcionais foi melhor que o outro.

Em geral, as patentes descritas citam o PHB como matriz e/ou substrato na confecção de biomateriais, conferindo-lhe diferentes propriedades comerciais e terapêuticas. Azevêdo et al. (2018), em sua revisão prospectiva, também constataram o interesse da comunidade científica no uso de biopolímeros, como filmes biodegradáveis, em substituição ao plástico convencional, principalmente em países como China e Estados Unidos.

\subsection{Análise dos Artigos Publicados}

O número de artigos científicos publicados com as palavras-chave nas bases científicas Web of Science, Scopus e Scielo nos últimos 10 anos está ilustrado na Tabela 3. Comparando-se com o número de patentes depositadas nos bancos nacionais e internacionais, constatou-se que o número de artigos científicos publicados com as palavras-chave "Norbixin", "Polyhydroxybutyrate", "Biomaterial", "Tissue Engineering" $e$ "Bone Repair" foi relativamente superior. 
Porém, a quantidade de publicações com norbixina ainda é reduzida quando comparada às demais palavras-chave pesquisadas.

Tabela 3 - Número de artigos encontrados com as palavras-chave nas bases científicas Web of Science, Scopus e Scielo nos últimos 10 anos

\begin{tabular}{cccc} 
Palavras-chave & Web OF Science & Scopus & Scielo \\
Norbixin & 94 & 100 & 5 \\
\hline Polyhydroxybutyrate & 1.330 & 1.222 & 44 \\
\hline Tissue engineering & 42.941 & 68.579 & 258 \\
\hline Biomaterial & 12.386 & 37.131 & 226 \\
\hline Bone repair & 20.853 & 22.988 & 270 \\
\hline
\end{tabular}

Fonte: Elaborada pelos autores deste artigo (2018)

A análise dos 100 artigos encontrados na base científica Scopus, a qual apresentou a maior quantidade de artigos publicados a partir da busca com a palavra-chave "Norbixin" nos últimos 10 anos, revelou que o ano com maior número de publicações foi 2012 (16 artigos), e o ano com menor número de publicações foi 2008 (2 artigos), conforme ilustrado na Figura 2.

Figura 2 - Artigos publicados nos últimos 10 anos para a palavra "Norbixin"

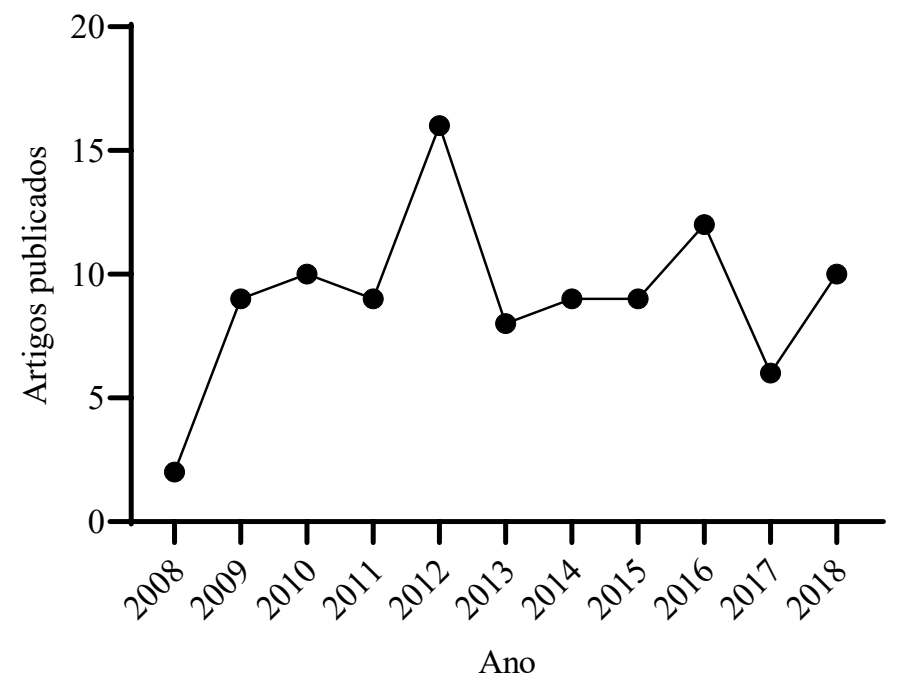

Fonte: Elaborada pelos autores deste artigo (2018)

Dos 100 artigos publicados com a palavra-chave "Norbixin", 32 tiveram origem nos Estados Unidos, 26 no Brasil, 11 na Índia, dentre outros em menores quantidades, sugerindo que os Estados Unidos têm se destacado e têm sido pioneiros em pesquisas nesta área, assim como o Brasil, que também tem se destacado em pesquisas na área (publicou 5 artigos em 2018), o que pode ser justificado pelo fato de a Bixa orellana L. ser nativa na América tropical e ter sido tradicionalmente utilizada pelos índios brasileiros para as mais diversas finalidades (VILAR et al., 2014). Observou-se que outros países, como a Índia, também têm realizado pesquisas recentes (ano de 2018) com esse antioxidante natural. 
Após um diagnóstico das principais áreas de publicações com essa palavra-chave, constatou-se que as maiores áreas de interesse para publicação são Agricultura (32,4\%), Bioquímica/ Genética e Molecular (19,5\%), Química (11,9\%), Medicina (8,1\%), Farmacologia e Toxicologia $(6,5 \%)$, Engenharia Química (5,4\%), dentre outras, revelando o desenvolvimento de pesquisas com o uso da norbixina em outras áreas de aplicação, como meios biológicos, além de Agricultura e Alimentos, conforme ilustrado na Figura 3.

Figura 3 - Principais áreas de publicações com a palavra-chave "Norbixin"

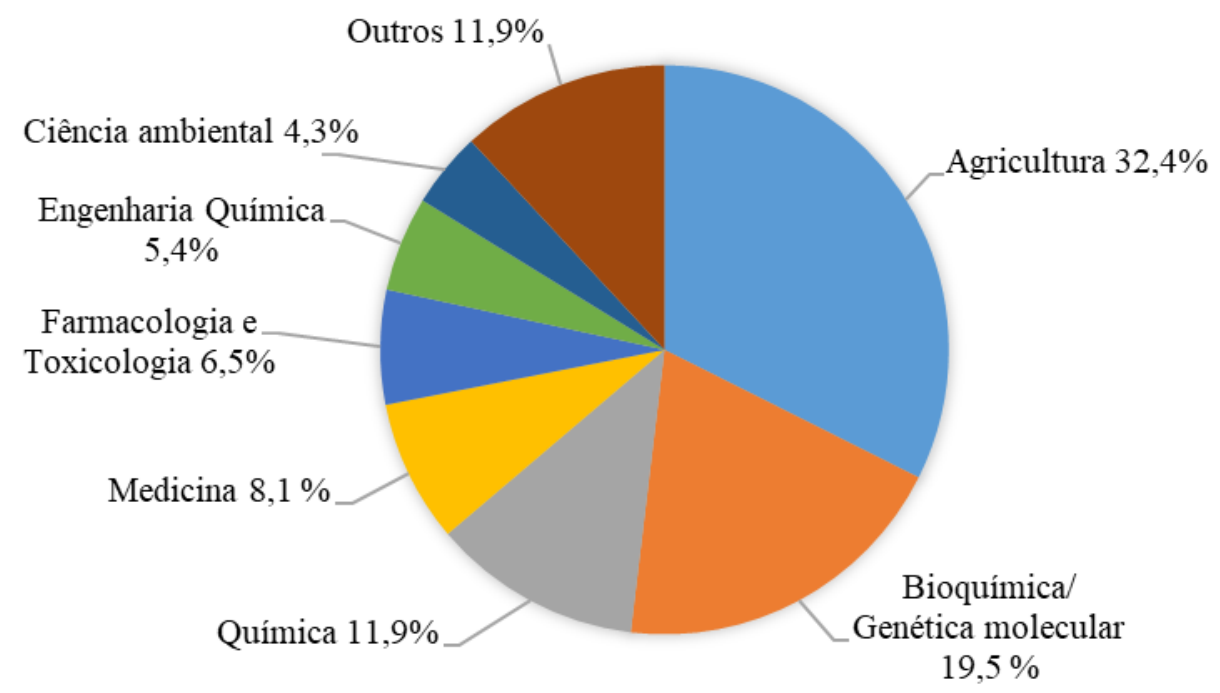

Fonte: Elaborada pelos autores deste artigo (2018)

A respeito do refinamento da pesquisa com combinação de palavras-chave nas bases Web of Science, Scopus e Scielo, conforme representado na Tabela 4, constatou-se que foram encontrados apenas dois artigos com as combinações envolvendo as palavras-chave "Norbixin" AND "Bone repair" e apenas um artigo para a busca "Norbixin" AND "Polyhydroxybutyrate", o qual já havia sido refinado na combinação imediatamente anterior a esta, demostrando que estudos com a utilização desse apocarotenoide para uso como biomaterial $e$ afins, bem como em conjunto com o poli-hidroxibutirato, são inovadores, e ainda pouco explorados.

Tabela 4 - Número de artigos publicados com as combinações das palavras-chave nas bases de dados Web of Science, Scopus e Scielo nos últimos 10 anos

\begin{tabular}{cccc} 
PalavRas-CHAVE & Web OF SCIENCE & Scopus & Scielo \\
Norbixin and biomaterial & 0 & 0 & 0 \\
\hline Norbixin and tissue engineering & 0 & 0 & 0 \\
\hline Norbixin and bone repair & 2 & 2 & 0 \\
\hline Norbixin and polyhydroxybutyrate & 1 & 1 & 0 \\
\hline Polyhydroxybutyrate and biomaterial & 21 & 59 & 4 \\
\hline Polyhydroxybutyrate and tissue engineering & 80 & 83 & 0 \\
\hline Polyhydroxybutyrate and bone repair & 11 & 7 & 0 \\
\hline
\end{tabular}

Fonte: Elaborada pelos autores deste artigo (2018) 
Ambos os artigos encontrados nas bases de dados Web of Science e Scopus para a combinação "Norbixin" AND "Bone Repair" foram publicados pelo grupo de pesquisa e por um grupo de pesquisadores relacionados à nossa linha de pesquisa.

Nesse contexto, Sousa et al. (2018) observaram que não existem estudos envolvendo a norbixina associada ao poli-hidroxibutirato como constituintes de biomembranas na cicatrização tecidual para reparo de feridas cutâneas ou regeneração óssea, embora ambos apresentem pesquisas promissoras que sugerem sua eficácia como guia para a regeneração tecidual.

Alves et al. (2018) avaliaram o efeito terapêutico da fotobiomodulação a laser de $780 \mathrm{~nm}$ (PBD) $\left(\lambda=780 \mathrm{~nm}, \mathrm{ED}=6 \mathrm{~J} / \mathrm{cm}^{2}, \mathrm{P}=60 \mathrm{~mW}, \mathrm{t}=4 \mathrm{~s}\right.$, no pós-operatório em dias alternados até a eutanásia) e uma membrana de poliestireno revestida com norbixina e colágeno (PSNC) na reparação óssea em ratos com defeito ósseo calvarial. Os grupos foram analisados após 15 e 30 dias de tratamento. Os autores concluíram que a membrana PSNC foi eficaz na redução do processo inflamatório e serviu como um scaffold para reparo ósseo. O laser PBM também apresentou efeitos positivos no processo de reparo ósseo, com maior deposição e organização do osso neoformado, porém, o laser PBM não melhorou as propriedades bioativas da estrutura óssea quando associado ao biomaterial.

Por outro lado, a utilização do PHB como biomaterial, especialmente quando utilizado na regeneração tecidual, mostrou-se bem conhecida. Da mesma forma, Rocha, Quintella e Torres (2012) também observaram que a classe de poli-hidroxialcanoatos, da qual o PHB faz parte, representou os biopolímeros mais citados na literatura para uso em medicina regenerativa.

Na Tabela 4, a busca na base de dados Scopus revelou um aumento nas publicações nos últimos anos, cujo ápice ocorreu em 2017 (13 artigos), conforme revelado na Figura 4.

Figura 4 - Artigos publicados nos últimos 10 anos para a combinação "Polyhydroxybutyrate" AND "Tissue Engineering"

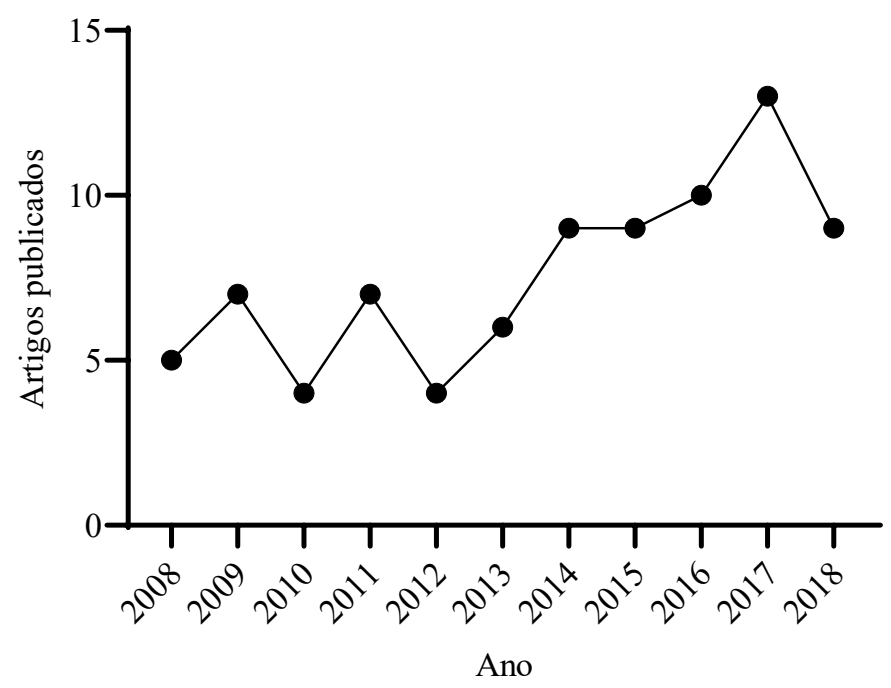

Fonte: Elaborada pelos autores deste artigo (2018)

Vale ressaltar que a área de Ciência e Engenharia dos Materiais $(26,1 \%)$ foi destaque nas publicações envolvendo "Polyhydroxybutyrate" AND "Tissue Engineering" no período avaliado, seguida de outras publicações, principalmente nas áreas de Bioquímica/Genética e Biologia Mo- 
lecular (15,4\%), Engenharia Química (13,8\%), Engenharia (13,8\%), Química (7,4\%), Ciências Agrárias e Biológicas (6,4\%) e Medicina (4,8\%), dentre outras (Figura 5).

Figura 5 - Principais áreas de publicações relacionadas à combinação das palavras-chave "Polyhydroxybutyrate" AND "Tissue Engineering" nos últimos 10 anos

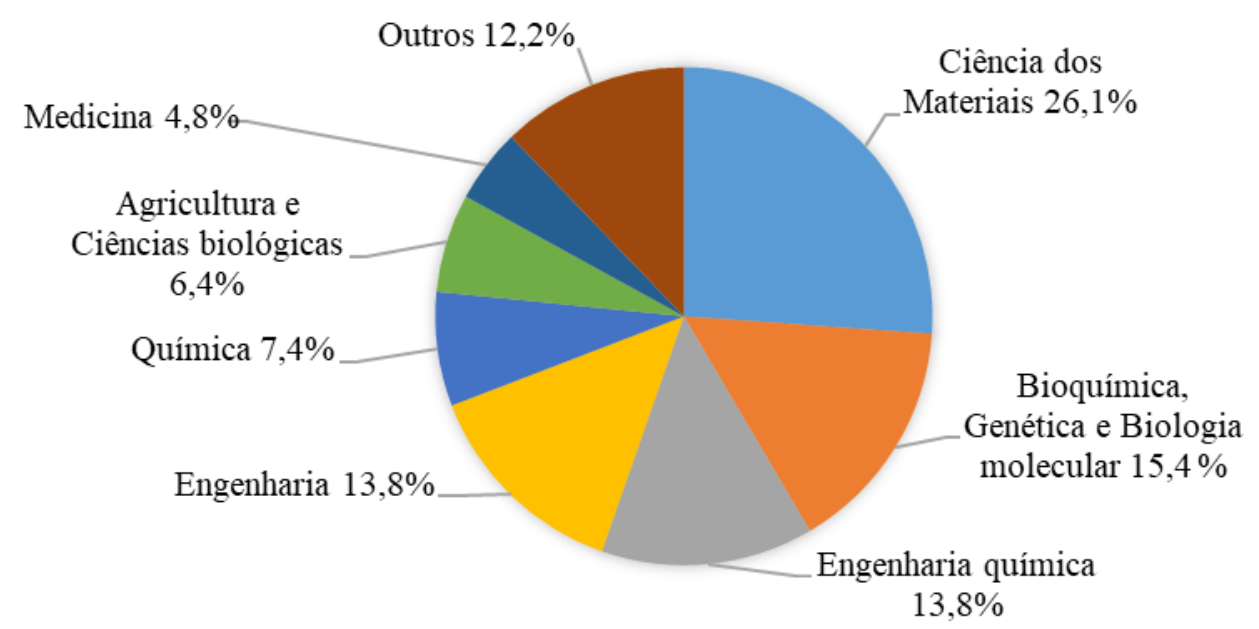

Fonte: Elaborada pelos autores deste artigo (2018)

Foram encontradas sete publicações no refinamento com as palavras-chave "Polyhydroxybutyrate" AND "Bone Repair" na base Scopus e 11 publicações na base Web of Science, das quais seis foram refinadas e encontradas em ambas as bases de dados.

Nesse contexto, todos os artigos refinados trataram de potenciais aplicações biológicas do PHB no reparo ósseo. Freg et al. (2008), por exemplo, avaliaram a capacidade de reparação óssea de um implante artificial à base de Nano-HA-PHBV/PEG (nano-hidroxiapatita, poli-hidroxibutirato-valerato e polietilenoglicol) em comparação a um implante de Nano-HA (nano-hidroxiapatita) puro em defeito crítico induzido em rádio de coelhos. Observou-se que Nano-HA-PHBV/PEG apresentou densidade óssea superior ao controle (Nano-HA) após oito semanas e resistência à flexão superior às $16^{\mathrm{a}}$ e $24^{\mathrm{a}}$ semanas de experimento, concluindo que Nano-HA-PHBV/PEG é mais favorável na habilidade de formação óssea e biocompatibilidade no reparo de defeito ósseo.

Li et al. (2008) estudaram a biocompatibilidade de compósitos degradáveis e bioativos compostos por PHBV incorporados com volastonite (PHBV/W) como scaffolds para a cultura de células osteoblásticas. Os resultados revelaram que a incorporação de volastonite (10 a $20 \%$ ) ao PHBV beneficiou a adesão de osteoblastos cultivados com maior proliferação e taxa de diferenciação quando comparado ao PHBV puro.

Ahmed et al. (2010) investigaram o enxerto de biomateriais à base de PHB e PHBV no ciclo de progressão de olfactory ensheathing cells (OECs) e mesenchymal stem cells (MSCs). PHB e PHBV foram biocompatíveis na análise do ciclo celular, não exibindo aberrações celulares, embora ambos também tenham estimulado precocemente apoptose e necrose. As linhagens celulares preferiram filmes de $\mathrm{PHBV}$ aos de $\mathrm{PHB}$, pois promoveram maior síntese e adesão celular do que nos filmes de PHB (redução na adesão e migração celular), especialmente MSCs. Esses autores ainda relataram que as propriedades físico-químicas dos materiais são importantes critérios de escolha para uso de dispositivos como biomaterial e observaram que filmes de 
PHBV são significativamente mais flexíveis que os de $\mathrm{PHB}$, o que pode estar relacionado à diferença no teor de cristalização.

Jacobs et al. (2013) buscaram melhorar a interação de cultura de células de fibroblastos de prepúcio humano (HFF) com filmes de PHB/PHV (poli-hidroxibutirato/poli-hidroxivalerato) tratados com plasma de média pressão operando em diferentes atmosferas (ar seco, argônio e hélio). Eles observaram que o tratamento com plasma reduziu o ângulo de contato e otimizou a molhabilidade dos polímeros, além de melhorar a adesão, proliferação e morfologia de HFF após sete dias de semeadura celular.

Sadat-Shojai et al. (2013) observaram que a incorporação de nanopartículas de HAp (hidroxiapatita) em PHB aumentou significativamente a proliferação e diferenciação de MC3T3-E1 em comparação ao polímero puro. Além disso, não foi encontrada nenhuma diferenciação celular no polímero puro, ao passo que nanocompósito com $15 \%$ de nHAp exibiu diferenciação significativa, a qual foi associada à alta rugosidade e grande quantidade de HAp exposta na superfície.

Wu et al. (2017) pesquisaram scaffolds para implante ósseo composto por PHBV-BG (poli-hidroxibutiratovalerato com adição de cerâmica de biovidro), o qual foi melhorado com cocultura de células endoteliais da veia umbilical humana (HUVECs) e células estromais da medula óssea (HBMSCs). Os resultados revelaram que a adição de $10 \%$ de BG aumentou a diferenciação osteogênica de HBMSCs e a vascularização de HUVECs pela regulação positiva de efeitos parácrinos em comparação aos scaffolds de PHBV puro. Em conjunto, os autores concluíram que os scaffolds de PHBV-BG com cocultura de células endoteliais e osteogênicas detêm grande potencial para reparo ósseo.

Wu et al. (2009) avaliaram a biocompatibilidade in vivo de $\mathrm{PHBV}$ purificado com $\mathrm{H}_{2} \mathrm{O}_{2}$, tratado e extraído com solvente e utilizado em modelo de defeito na tíbia de murinos, o qual consiste de um buraco perfurado através do diâmetro da diáfise da tíbia em que foram implantados tampões cilíndricos não porosos de PHBV purificado. Os resultados indicaram que o PHBV sólido induz uma reação tecidual leve com depósito ósseo adjacente ao implante sem tecido fibroso presente nas quatro semanas após o procedimento cirúrgico.

Kwiatkowska et al. (2012) avaliaram compósitos biodegradáveis e bioativos com ácido poliláctico (PLA) ou poli-e-caprolactona (PCL) como matriz e fibras bioplásticas contendo $\mathrm{PHB}$ como reforço diante da linhagem celular de fibroblastos. Estes autores observaram que os compósitos feitos de PLA e fibras de linho transgênicos apresentaram propriedades bacteriostáticas, antiagregação plaquetária e efeitos não tóxicos. Além disso, houve crescimento celular de fibroblastos sobre a superfície dos compósitos com boa proliferação celular e viabilidade entre 86 e 95\%. A determinação do nível de agregação plaquetária na superfície dos compósitos preparados e o nível de sua colonização por bactérias Escherichia coli mostraram que os compósitos possuíam propriedades antiagregantes e bacteriostáticas, o que indicou seu potencial para aplicações médicas.

Além disso, foram desenvolvidas membranas absorvíveis, porém rígidas (membranas de hidroxiapatita a 25\% (HA) em matriz de poli-hidroxibutirato (PHB) ou HA a 35\% em PHB), as quais foram analisadas em regeneração periodontal em defeitos de furcação classe II em cães por Reis et al. (2012). Os autores observaram que houve regeneração parcial do defeito, porém essa regeneração foi limitada pela contaminação da ferida. 
Já Buffa et al. (2015) investigaram a preparação, caracterização e citotoxicidade de um material nanocompósito híbrido feito de nanotubos de halosito carregados com Sr (II) (HNT) incluídos em uma matriz de biopolímero (3-poli-hidroxibutirato-co-3-hidroxivalerato) (PHBV). De acordo com esses pesquisadores, a degradação do polímero leva progressivamente à exposição da estrutura de haloisito carregada com Sr (II), sintonizando sua interação com as células osteogênicas. A biocompatibilidade in vitro do compósito foi demonstrada por testes de citotoxicidade em células de fibroblastos L929 pelo teste MTT após 72h de exposição em diferentes concentrações de compósitos $(25,50$ e $100 \mu \mathrm{g} / \mathrm{mL})$, com viabilidade celular $>80 \%$ para todos os grupos avaliados (HNT, HNT-PHBV e HNT-Sr-PHBV). Além disso, a proliferação celular também foi mantida após $48 \mathrm{~h}$ de incubação com diferentes suspensões de todos os grupos avaliados.

Por fim, Khoshraftar et al. (2018) avaliaram os arcabouços de nanocompósitos de poli (3-hidroxibutirato-co-3-hidroxivalerato) (PHBV) e nano-hidroxiapatita ( $\mathrm{nHA}$ ) (PHBV/nHA) em diferentes proporções de nHA para a regeneração óssea. Eles observaram que o teste de degradabilidade dos scaffolds apresentou baixa taxa de degradação (degradação total de 30\% após 3 meses); quanto à citotoxicidade, as células osteoblásticas (MC3T3) cultivadas em scaffolds com nanocompósitos apresentaram maior proliferação e fixação em relação ao scaffold PHBV; o suporte de nanofibras contendo hidroxiapatita apresentou a maior atividade de fosfatase alcalina como resultado de melhor proliferação. Portanto, esses autores recomendam que os suportes de PHBV/nHA sejam candidatos adequados para a engenharia de tecido ósseo.

Corroborando com os resultados descritos, Rocha, Quintella e Torres (2012) observaram uma tecnologia emergente a partir de polímeros biocompatíveis empregados como biomateriais na medicina regenerativa. O poli-hidroxibutirato foi avaliado como matriz polimérica em estudos experimentais in vivo e in vitro, além de diversos estudos de caracterizações fisicoquímicas associados, que por sua vez avaliaram a otimização das propriedades deste polímero no âmbito da ciência e engenharia dos materiais quando reforçado com outros tipos de materiais nos biocompósitos desenvolvidos e analisados a partir do PHB. Todas as pesquisas destacaram características importantes dos biomateriais supracitados para o tratamento de reparo ósseo, como biodegradação, bioabsorção e scaffold para osteoindução.

Não foram encontrados patentes e/ou estudos experimentais que envolvessem o biomaterial à base de poli-hidroxibutirato e norbixina para fins de reparo ósseo, embora seja conhecida a sua propriedade não genotóxica em meio biológico, bem como a sua fácil disponibilidade na natureza (SOUSA et al., 2016). Trata-se de uma biotecnologia ainda desconhecida na literatura no contexto do tema deste artigo. Ainda assim, observou-se que o poli-hidroxibutirato $e$ a norbixina apresentaram benefícios na área de engenharia de tecidos, assim como para fins de regeneração óssea, nos diversos estudos experimentais relatados, ainda que associados a outros diferentes materiais. Logo a associação de ambos representa uma promissora área de pesquisa a ser explorada.

\section{Considerações Finais}

Nos últimos 10 anos, foi crescente o número de pesquisas científicas relacionadas à aplicação do polímero poli-hidroxibutirato na área de engenharia de tecidos e reparo ósseo. Os resultados apresentados com o mapeamento tecnológico revelaram que a associação do polímero poli-hi- 
droxibutirato ao apocarotenoide norbixina para uso como biomaterial em regeneração óssea ainda é desconhecida e, até o presente momento, inédita, visto que não foram encontrados estudos científicos e/ou experimentais ou patentes com uma abordagem semelhante com as combinações de palavras-chave propostas.

Contudo, o emprego de tal polímero na engenharia de tecidos como material biocompatível, assim como a utilização de norbixina na indústria alimentícia e farmacêutica com propriedades antioxidantes, são conhecidos em meio biológico, o que pode representar uma associação promissora, fazendo-se necessários ensaios experimentais para sua aprovação.

\section{Referências}

AARTHI, N.; RAMANA, K. V. Identification and Characterization of Polyhydroxybutyrate producing Bacillus cereus and Bacillus mycoides strains. International Journal of Environmental Sciences, [S.l.], v. 1, p. 744-756, 2011.

AHMED, T. et al. Polyhydroxybutyrate and its Copolymer with Polyhydroxyvalerate as Biomaterials: Influence on Progression of Stem Cell Cycle. Biomacromolecules, [S.l.], v. 11, p. 2.707-2.715, 2010.

ALVES, A. M. M. et al. Evaluation of bone repair after application of a norbixin membrane scaffold with and without laser photobiomodulation $(\lambda 780 \mathrm{~nm})$. Lasers Medical in Science, $[S .1]$, v. 33, n. 7, p. 1.493-1.504, 2018.

AZEVÊDO, L. C. et al. Propriedades do amido e suas aplicações em biopolímeros. Cadernos de Prospecção, [S.l.], v. 11, p. 351-358, 2018.

BUFFA, S. D. et al. Desing and characterization of a composite material based on Sr (II)-loaded clay nanotubes included within a polymer matrix. Journal of Colloid and Interface Science, [S.I.], v. 448, p. 501-507, 2015.

COSTA, C. L. S.; CHAVES, M. H. Extração de pigmentos das sementes de Bixa orellana L.: uma alternativa para disciplinas experimentais de química orgânica. Química Nova, [S.l.], v. 28, p. 149152, 2005.

CHR. HANSEN NATURAL COLORS A/S. KOEHLER, K.; NIELSEN, L. M. Composição compreendendo norbixina como um pigmento vermelho alaranjado. $\mathrm{DK} n$.

BR1120140279110A2. 8 maio, 2013, 26 jun. 2017. Disponível em: https://gru.inpi.gov.br/pePI/jsp/ patentes/PatenteSearchBasico.jsp. Acesso em: 25 set. 2018.

DONGHUA UNIVERSITY. YANG, Q. et al. Three-dimension porous tissue engineering carrier material and preparation and application. CN n. CN101147812 (A). 30 out. 2007, 26 mar. 2008. Disponível em: https://worldwide.espacenet.com/patent/search. Acesso em: 25 set. 2018.

ESPACENET. [Base de dados - Internet]. European Patent Office. 2018. Disponível em: https:// worldwide.espacenet.com/. Acesso em: 25 set. 2018.

FEDERAL NEW BUDGETARY INSTITUTION. VALER'YEVNA, A. L. et al. Method for making bioresorbed small-diameter hybrid vascular graft. RU n. RU2504406 (C1). 21 nov. 2012 , 20 jan. 2014. Disponível em: https://worldwide.espacenet.com/patent/search. Acesso em: 25 set. 2018. 
FENG, W. et al. Nano-hydroxyapatite-polyhydroxybutyrate valerate/polyethylene glycol artificial bone in bone defect repair. Journal of Clinical Rehabilitative Tissue Engineering Research, [S.l.], v. 12, n. 41, p. 8.025-8.028, 2008.

FERREIRA, E. L. Processo de fabricação de extratos vegetais corantes modificados com extrato de tanino. BR n. PI0005165-9A2. 25 out. 2000, 4 jun. 2002. Disponível em: https://gru. inpi.gov.br/pePI/jsp/patentes/PatenteSearchBasico.jsp. Acesso em: 25 set. 2018.

HENAN INSTITUTE OF ENGINEERING. XIANG, Y. et al. Preparation method of nano hydroxyapatite grafted polyhydroxybutyrate-hydroxyvalerate (PHBV). CN n. CN105582577 (A). 26 fev. 2016, 18 maio 2016. Disponível em: https://worldwide.espacenet.com/ patent/search. Acesso em: 25 set. 2018.

INPI - INSTITUTO NACIONAL DA PROPRIEDADE INDUSTRIAL. [Base de dados - Internet]. 2018. Disponível em: https://www.inpi.gov.br/. Acesso em: 25 set. 2018.

JACOBS, T. et al. Enhanced cell-material interactions on medium-pressure plasmatreated polyhydroxybutyrate/polyhydroxyvalerate. Journal of Biomedical Materials Research Part A, [S.l.], v. 101A, p. 1.778-1.786, 2013.

KHOSHRAFTAR, A. et al. Fabrication and evaluation of nanofibrus polyhydroxybutyrate valerate scaffolds containing hydroxyapatite particles for bone tissue engineering. International Journal of Polymeric Materials and Polymeric Biomaterials, [S.I.], v. 67, p. 987-995, 2018.

KWIATKOWSKA, M. W. et al. New biocomposites based on bioplastic flax fibers and biodegradable polymers. Biotechnology Progress, [S.I.], v. 28, n. 5, p. 1.336-1.346, 2012.

LEVY, L. W.; BINNINGTON, R. H.; TABATZNIK, A. S. Novos ésteres carotenoides. UK n. PI0207405-2B1. 22 fev. 2002, 2 mar. 2004. Disponível em: https:/gru.inpi.gov.br/pePI/jsp/patentes/ PatenteSearchBasico.jsp. Acesso em: 25 set. 2018.

LI, H.; ZHAI, W.; CHANG, J. In vitro biocompatibility assessment of PHBV/Wollastonite composites. Journal of Materials Science: Materials in Medicine, [S.I.], v. 19, p. 67-73, 2008.

MACHADO, M. L. C. et al. Estudo das propriedades mecânicas e térmicas do polímero Poli-3Hidroxibutirato (PHB) e de compósitos PHB/pó de madeira. Polímeros, [S.l.], v. 20, n. 1, p. 65-71, 2010.

MELO, J. D. D. et al. A biodegradable composite material based on polyhidroxybutyrate (PHB) and carnauba fibers. Composites: Part B, [S.l.], v. 43, p. 2.827-2.835, 2012.

MONTE, S. M. et al. Genotoxicity Evaluation of Polystyrene membrane with Collagen and Norbixin by Micronucleus Test and Comet Assay. International Journal of Pharmaceltical Science Invention, [S.I.], v. 5, n. 4, p. 7-11, 2016.

MUTHUKUMAR, T. et al. Preparation, characterization, and in vitro bioactivity of Bixa Orellana extract-impregnated collagen microspheres. Journal of Materials Science, [S.l.], v. 49, p. 5.7305.737, 2014.

NASCIMENTO, T. G. et al. Patentes e apropriação de valor da inovação: o caso do própolis. Cadernos de Prospecção, Salvador, v. 11, n. 1, p. 87-102, 2018.

NORTHWEST NORMAL UNIVERSITY DIE et al. Method for preparing polyhydroxybutyratebased hybrid material. CN n. CN103113726 (A). 18 jan. 2013, 22 maio 2013. Disponível em: https://worldwide.espacenet.com/patent/search. Acesso em: 25 set. 2018. 
NORTHWEST NORMAL UNIVERSITY. JUNLONG, W. et al. Synthetic method of polyhydroxybutyrate-artemisia sphoerocephala polysaccharide copolymer. $\mathrm{CN} n$.

CN103275328 (A). 14 ju. 2013, 4 set. 2013. Disponível em: https://worldwide.espacenet.com/patent/ search. Acesso em: 25 set. 2018.

ORÉFICE, R. L.; PEREIRA, M. M.; MANSUR, H. S. Biomateriais: fundamentos e aplicações. Rio de Janeiro: Guanabara Koogan, 2012.

PIRES, A. L. R.; BIERHALZ, A. C. K.; MORAES, A. M. Biomateriais: tipos, aplicações e mercado. Química Nova, [S.l.], v. 38, n. 7, p. 957-971, 2015.

POLITEHNICA UNIVERSITY OF BUCHAREST. OCTAVIAN, S. P. et al. Composition based on polyhydroxybutyrate and bacterial celulose with applications in tissue engineering and process for preparing it. $\mathrm{RO}$ n. RO130767 (A0). 3 dez. 2014, 30 dez. 2015. Disponível em: https:// worldwide.espacenet.com/patent/search. Acesso em: 25 set. 2018.

REIS, E. C. C. et al. Desenvolvimento e caracterização de membranas rígidas, osteocondutoras e reabsorvíveis de polihidroxibutirato e hidroxiapatita para regeneração periodontal. Polímeros, [S.l.], v. 22 , n. 1 , p. 73-79, 2012.

ROCHA, A. M.; QUINTELLA, C. M.; TORRES, E. A. Prospecção de artigos e patentes sobre Polímeros biocompatíveis aplicados à engenharia de tecidos e medicina regenerativa. Cadernos de Prospecção, Salvador, v. 5, n. 2, p. 72-85, 2012.

SADAT-SHOJAI, M. et al. Nano-hydroxyapatite reinforced polyhydroxybutyrate composites: A comprehensive study on the structural and in vitro biological properties. Materials Science and Engineering C, [S.I.], v. 33, p. 2.776-2.787, 2013.

SANTOS, J. A. A. et al. Avaliação histomorfométrica do efeito do extrato aquoso de urucum (norbixina) no processo de cicatrização de feridas cutâneas em ratos. Revista Brasileira de Plantas Medicinais, [S.l.], v. 16, p. 637-643, 2014.

SCIELO. [Base de dados - Internet]. Scielo. 2018. Disponível em: http://www.scielo.org/php/index. php. Acesso em: 30 set. 2018.

SCOPUS. [Base de dados - Internet]. Scopus. 2018. Disponível em: https://www.scopus.com/. Acesso em: 30 set. 2018.

SOUSA, R. C. et al. Assessment of genotoxicity PHB/Norbixin/Etilenoglicol membrane by micronucleus test and comet assay. Journal of Biotechnology and Biochesmitry, [S.1.], v. 2, n. 7, p. 34-39, 2016.

SOUSA, R. C. et al. Poly (hydroxybutyrate) and norbixin as biomaterial in biological applications. Reviews on Advanced Materials Science, [S.1.], v. 53, p. 218-225, 2018.

SOUTHEAST UNIVERSITY. LANXIN, L. V; HUANG, N.; Zhang, X. Manufacturing method of composite nanofiber scaffold for promoting repair of bone defect. $\mathrm{CN} \mathrm{n}$. CN102166372 (A), 14 fev. 2011, 31 ago. 2011. Disponível em: https://worldwide.espacenet.com/patent/search. Acesso em: 25 set. 2018.

SOUTHEAST UNIVERSITY. NINGPING, H.; LANXIN, L. V.; XIAOFENG, Z. Preparation method for degradable three dimensional fiber scaffold capable of promoting repair of bone defects. CN n. CN102973981 (A). 19 out. 2012, 20 mar. 2013. Disponível em: https://worldwide.espacenet. com/patent/search. Acesso em: 25 set. 2018. 
SUZHOU NABEITONG ENVIROMENTAL TECHNOLOGY CO. LTD. MINGHUA, P. Injectable bone repairing material and preparation method thereof. $\mathrm{CN} n$. CN106581774 (A). 9 dez. 2016, 26 abr. 2017. Disponível em: https://worldwide.espacenet.com/patent/search. Acesso em: 25 set. 2018.

TEIXEIRA, A. S. N.; TEIXEIRA, P. R. S.; EIRAS, C. Uso de nanopartículas do mesocarpo do babaçu (Orbignya phalerata Mart) como plataforma para ancoragem de enzimas no desenvolvimento de biossensores: um mapeamento tecnológico. Revista Geintec, [S.l.], v. 8, p. 4.217-4.230, 2018.

TSINGHUA UNIVERSITY. YU, H. et al. Absorbable suture containing PHBHHx/PLA (poly-3hydroxybutyrate-co-3-hydroxyhexanoate/polylactic acid). CN n. CN105063789 (A). 30 out. 2013, 18 nov. 2015. Disponível em: https://worldwide.espacenet.com/patent/search. Acesso em: 25 set. 2018.

UFMG - UNIVERSIDADE FEDERAL DE MINAS GERAIS. MILLÁN, R. D. S.; GARCÍA, A. D. P.; ORLANDO, M. R. Universidade Federal de Minas Gerais. Nanodispositivos poliméricos carregados com agentes antioxidantes, quelantes, redutores e/ou adsorventes e usos. BR n. BR1020160299799A2. 20 dez. 2016, 26 fev. 2019. Disponível em: https:/gru.inpi.gov.br/pePI/jsp/ patentes/PatenteSearchBasico.jsp. Acesso em: 25 set. 2018.

UFRGS - UNIVERSIDADE FEDERAL DO RIO GRANDE DO SUL et al. Processo de obtenção de membrana eletrofiada, membrana obtida pelo referido processo, composição e processo de regeneração ex-vivo. Brazil patent. BR1020150174357A2. 17 jul. 2015,18 jul. 2017. Disponível em: https://gru.inpi.gov.br/pePI/jsp/patentes/PatenteSearchBasico.jsp. Acesso em: 25 set. 2018.

UNIVERSITE PARIS 6 PIERRE ET MARIE CURIE. LAFONT, R. et al. Composição. FR. BR1120170232642A2. 28 abr. 2016, 7 ago. 2018. Disponível em: https://gru.inpi.gov.br/pePI/jsp/ patentes/PatenteSearchBasico.jsp. Acesso em: 25 set. 2018.

USPTO. [Base de dados - Internet]. Unites State Patent and Trademark Office. 2018. Disponível em: https://uspto.gov.br/. Acesso em: 25 set. 2018.

FEDERAL STATE BUDGET SCIENTIFIC INSTITUTION. VALER'YEVNA, A. L. et al. Tissueengineering biodegradable vascular implant. RU n. RU2016123645 (A). 14 jun. 2016, 19 dez. 2017. Disponível em: https://worldwide.espacenet.com/patent/search. Acesso em: 25 set. 2018.

VILAR, D. A. et al. Traditional Uses, Chemical Constituents, and Biological Activities of Bixa orellana L.: A Review. Scientific World Journal, [S.I.], v. 2.014, p. 1-11, 2014.

VISCONFAN - INDÚSTRIA NAVARRA DE ENVOLTURAS CELULÓSICAS S.A. PECINA, J. J. G.; ARESO, C. L. Invólucro de celulose, método para o revestimento da superfície interna dos invólucros de celulose regenerada, salsicha colorida e método para revestir salsichas. ES n. PI9500660-5B1. 16 fev. 1995, 24 out. 1995. Disponível em: https://gru.inpi.gov.br/pePI/jsp/patentes/ PatenteSearchBasico.jsp. Acesso em: 25 set. 2018.

WEB OF SCIENCE. [Base de dados - Internet]. Scopus. 2018. Disponível em: https:// http://appswebofknowledge.ez17.periodicos.capes.gov.br/. Acesso em: 30 set. 2018.

WENFANG, X. Fast-mounting self-locking pipe fitting. CN n. CN2475908 (Y). 11 abr. 2000, 6 fev. 2002. Disponível em: https://worldwide.espacenet.com/patent/search. Acesso em: 25 set. 2018.

WU, J. et al. PHBV/bioglass composite scaffolds with cocultures of endothelial cells and bone marrow stromal cells improve vascularization and osteogenesis for bone tissue engineering. Royal Society of Chemistry Advances, [S.I.], v. 7, p. 22.197-22.207, 2017. 
WU, C. K. A. et al. Responses in vivo to purified poly (3-hydroxybutyrate-co-3-hydroxyvalerate) implanted in a murine tibial defect model. Journal of Biomedical Materials Research A., [S.l.], v. 91, n. 3, p. 845-54, 2009.

ZHANG, Y.; ZHONG, Q. Probing the biding between norbixina and dairy proteins by spectroscopy methods. Food Chemistry, [S.l.], v. 139, p. 611-616, 2013.

\section{Sobre os Autores}

\section{Rayssilane Cardoso de Sousa}

E-mail: rayssilane14@hotmail.com

Mestrado em Engenharia de Materiais pelo Instituto Federal de Educação, Ciências e Tecnologia do Piauí (2017).

Endereço profissional: Quadra 114, casa 8, Dirceu Arcoverde 1, Teresina, PI. CEP: 64077-343.

\section{Vicente Galber Freitas Viana}

E-mail: galber@ifpi.edu.br

Doutorado em Ciências (Física Aplicada) pelo Instituto de Física de São Carlos/USP (2006).

Endereço profissional: Praça da Liberdade, n. 1.597, Centro (Sul), Teresina, PI. CEP: 64000-000.

\section{Luiz Fernando Meneses Carvalho}

E-mail: luizfmc01@gmail.com

Doutorado em Ciências e Engenharia dos Materiais pela Universidade Federal do Rio Grande do Norte (2011).

Endereço profissional: Praça da Liberdade, n. 1.597, Centro (Sul), Teresina, PI. CEP: 64000-000.

\section{Daniel Fernando Pereira Vasconcelos}

E-mail: vasconcelos@ifpi.edu.br

Doutorado em Odontologia pela Universidade Estadual de Campinas (2008).

Endereço profissional: Avenida São Sebastião, n. 2.819, Parnaíba, PI. CEP: 64202-020. 